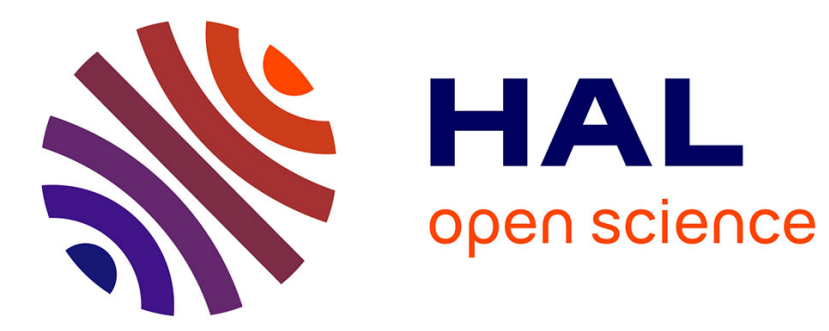

\title{
Totally implantable venous access port systems and risk factors for complications: A one-year prospective study in a cancer centre
}

F. Narducci, M.J. Laurent, L. Boulanger, S. El Bédoui, Y. Mallet, J.L. Houpeau, A. Hamdani, N. Penel, Clarisse Fournier

\section{To cite this version:}

F. Narducci, M.J. Laurent, L. Boulanger, S. El Bédoui, Y. Mallet, et al.. Totally implantable venous access port systems and risk factors for complications: A one-year prospective study in a cancer centre. EJSO - European Journal of Surgical Oncology, 2011, 37 (10), pp.913. 10.1016/j.ejso.2011.06.016 . hal-00732666

\section{HAL Id: hal-00732666 \\ https://hal.science/hal-00732666}

Submitted on 16 Sep 2012

HAL is a multi-disciplinary open access archive for the deposit and dissemination of scientific research documents, whether they are published or not. The documents may come from teaching and research institutions in France or abroad, or from public or private research centers.
L'archive ouverte pluridisciplinaire HAL, est destinée au dépôt et à la diffusion de documents scientifiques de niveau recherche, publiés ou non, émanant des établissements d'enseignement et de recherche français ou étrangers, des laboratoires publics ou privés. 


\section{Accepted Manuscript}

Title: Totally implantable venous access port systems and risk factors for complications: A one-year prospective study in a cancer centre

Authors: F. Narducci, M.J. Laurent, L. Boulanger, S. El Bédoui, Y. Mallet, J.L. Houpeau, A. Hamdani, N. Penel, C. Fournier

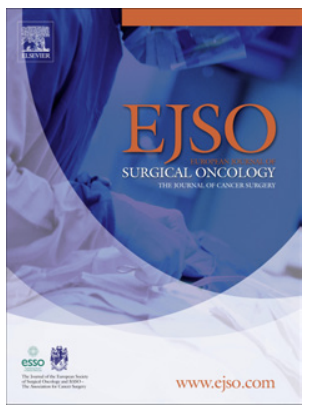

PII:

S0748-7983(11)00353-2

DOI:

10.1016/j.ejso.2011.06.016

Reference: $\quad$ YEJSO 3190

To appear in: European Journal of Surgical Oncology

Accepted Date: 28 June 2011

Please cite this article as: Narducci F, Laurent MJ, Boulanger L, El Bédoui S, Mallet Y, Houpeau JL, Hamdani A, Penel N, Fournier C. Totally implantable venous access port systems and risk factors for complications: A one-year prospective study in a cancer centre, European Journal of Surgical Oncology (2011), doi: 10.1016/j.ejso.2011.06.016

This is a PDF file of an unedited manuscript that has been accepted for publication. As a service to our customers we are providing this early version of the manuscript. The manuscript will undergo copyediting, typesetting, and review of the resulting proof before it is published in its final form. Please note that during the production process errors may be discovered which could affect the content, and all legal disclaimers that apply to the journal pertain. 


\section{Totally implantable venous access port systems and risk factors for} complications: a one-year prospective study in a cancer centre

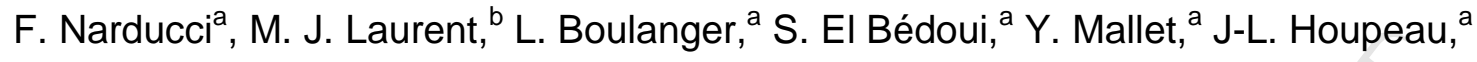

A. Hamdani, ${ }^{a}$ N. Penel, ${ }^{a}$ C. Fournier ${ }^{a}$

${ }^{a}$ Centre Régional de Lutte Contre le Cancer Oscar Lambret, 3 rue Frédéric

Combemale, BP 307, 59020 Lille Cedex, France

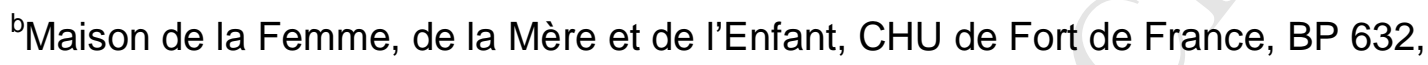
97261 Fort de France Cedex, Martinique

\section{Corresponding author:}

Dr Fabrice Narducci

Centre Régional de Lutte Contre le Cancer Oscar Lambret

Département de Cancérologie Gynécologique

3 rue Frédéric Combemale

BP307

59020 LILLE Cedex

France

e-mail: f-narducci@o-lambret.fr

tel.: + 33320295944

fax: + 33320295928 


\section{Abstract}

Background: Totally Implantable Venous Access Port Systems (TIVAPS) are widely used in oncology, but complications are frequent, sometimes necessitating device removal and consequently delays in chemotherapy. The aim of this study was to investigate possible risk factors for morbidity.

Methods: A total of 815 consecutive cancer patients (median age: 56.2 years [0.885.2]; 522 female) were enrolled in this observational, single-centre study between May $2^{\text {nd }} 2006$ and April $30^{\text {th }} 2007$. TIVAPS implantation involved principally cephalic or external jugular vein access. Patients were followed up for one year unless the device was removed earlier.

Results: The overall morbidity rate was $16.1 \%$ (131/815). Complications necessitated device removal in 55 patients a mean of 3.7 months [0.2-12.0] after implantation. These comprised TIVAPS-related infection (19), port expulsion (14), catheter migration (6), venous thrombosis (5), mechanical problems (3), skin disorders (2), pain (2), drug extravasation (2) infection unrelated to TIVAPS (1) and inflammation (1). No patient died during the study. The factor most strongly predictive of complications was the interval between insertion and first use of the TIVAPS, ranging from 0 to 135 days (median: 8.0 days). The morbidity rate was $24.4 \%$ when this interval was $0-3$ days, $17.1 \%$ when it was $4-7$ days and $12.1 \%$ when it exceeded 7 days $\left(p<0.01 ;\right.$ Chi $^{2}$ test). The median interval was 6 days (0-53) and 8 days ( 0 135), respectively, in patients with and without complications $(\mathrm{p}<0.001)$.

Conclusion: To reduce complications, an interval of at least 8 days between placement of the TIVAPS and its first use may be advisable. 
Page $3 / 23$

Keywords: Observational study; Cancer patients; Totally implantable venous access port systems; Complications 


\section{Introduction}

First introduced in the early 1980 s, totally implantable venous access port systems (TIVAPS) are now routinely used in oncology, facilitating long-term chemotherapy and other precedures.[1,2]

Although TIVAPS are generally associated with a lower long-term risk of infection compared to Hickman-type central venous catheters, $[3,4]$ complications during their placement and long-term use are still a matter of concern. These complications, including infection, catheter fracture, thrombosis and extravasation [5,6,7], may necessitate device replacement, resulting in additional patient stress and treatment delays. Cancer patients have an intrinsically high risk of venous thrombosis, related to both the disease process itself and certain cancer treatments,[8] this risk being further increased by placement of a catheter or TIVAPS.[1]

Several studies in cancer patients have investigated potential risk factors for TIVAPS-related complications, including the vein accessed $[5,9,10]$ and patient age and gender [11,12], with somewhat conflicting results. Yildizeli et al. found no significant difference in the rates of early or late complications according to the vein catheterised (internal jugular, subclavian or cephalic), but failed attempts at catheter placement were significantly fewer with subclavian vein access.[5] Biffi et al. similarly detected no difference in complication rate between cephalic and subclavian vein access [6]. Vardy et al. reported successful catheter placement via the subclavian vein in practically all patients, with low complication rates.[9] However, Araújo et al. showed lower rates of immediate complications, catheter malpositioning, long-term morbidity (including venous thrombosis) and catheter malfunction with internal jugular vein rather than subclavian vein access.[10] A retrospective analysis of factors 
associated with TIVAPS failure by Hsieh et al. did not indicate a significant impact of insertion site, but identified increasing age, male gender and open-ended catheters as statistically significant risk factors.[11] In contrast, Hung et al., in a retrospective analysis of paediatric patients, showed a higher risk of infection after TIVAPS implantation in younger patients.[12]

In view of the importance of minimising complications associated with TIVAPS and the few data available on potential risk factors, we initiated a large-scale prospective, observational study to explore this issue in the context of routine clinical practice in our cancer treatment centre.

\section{Patients and methods}

\section{Study design}

This was a prospective, observational, descriptive study of the insertion and use of TIVAPS in a specialised cancer treatment center. The primary objective was to determine the complications associated with TIVAPS during the year following their insertion and to analyse the risk factors for these. The complications assessed were specified prior to the study in the protocol and case report form (CRF). The secondary objective was to evaluate patient satisfaction with TIVAPS placement (particularly in terms of pain, discomfort and aesthetic outcome) and quality of life.

Inclusion and exclusion criteria

Adult and paediatric patients with documented cancer treated in the Oscar Lambret Regional Anticancer Centre (Lille, France) and requiring long-term venous access were eligible to enter the study provided they met none of the specified exclusion criteria. These comprised medical contraindication to surgical intervention 
under local or general anaesthesia, history of allergy to lidocaine, clinical evidence of superior vena cava syndrome, clinical, biological or medication-related contraindication to TIVAPS placement, or geographical, social or psychological obstacle to the medical follow-up envisaged.

The study was approved by the Ministry of Education, Research and Technology (Ministère de l'Education Nationale, de la Recherche et de la Technologie and the National Commission for Computerisation and Freedom (Commission Nationale de I'Informatique et des Libertés - CNIL), Ethics Committee approval not being required in France for this type of observational study. Patients received detailed information about the study and informed consent was obtained from all participants.

\section{Evaluation criteria}

$\underline{\text { Incidence of complications and potential risk factors (primary endpoint) }}$

The likely complications, predefined in the protocol and CRF, comprised local haematoma, inflammation, wound discharge, non-resorption of stitches, pain (in general and on injection), catheter obstruction, catheter rupture, thrombotic syndrome, extravasation of the product injected, documented infection, haemothorax or pneumothorax, port flip and port expulsion. Complications related to TIVAPS placement and necessitating an emergency consultation were recorded by the surgeon responsible for device insertion. Complications during TIVAPS use were recorded by the medical oncologist during the consultations preceding each chemotherapy session, as well as by the medico-surgical team during monitoring consultations. 
Parameters potentially constituting risk factors for complications, including patient characteristics, hygiene, TIVAPS insertion procedure, conditions of use of the TIVAPS, and interval between insertion and first use, were also recorded.

\section{Quality of life and patient satisfaction (secondary endpoints)}

Quality of life was assessed in adult patients by the European Organization for Research and Treatment of Cancer (EORTC) questionnaire QLC-C30, completed just before TIVAPS insertion and the start of the first and fourth chemotherapy cycles. Patients also completed a self-assessment questionnaire just before the start of the fourth chemotherapy cycle to evaluate their satisfaction with TIVAPS insertion and use, and tolerance of these procedures. This questionnaire focused particularly on post-operative pain, discomfort caused by the implantation scar or the port chamber, and the aesthetic impact of the scar and subcutaneous trajectory of the catheter.

\section{Statistical analysis}

Qualitative variables were expressed as the median and range, and the mean and standard deviation. Qualitative variables were expressed in terms of their absolute and percentage frequency. Univariate analyses (Student's t test and chi ${ }^{2}$ test) and multivariate logistic regression analyses were used to determine the risk factors for complications. Scores on the EORTC quality of life questionnaire were compared by the Student's t test and Wilcoxon's test, and scores on the satisfaction questionnaire by the $\mathrm{chi}^{2}$ test. 


\section{Results}

\section{Patient population}

A total of 815 consecutive cancer patients (552 female) undergoing TIVAPS placement and meeting the specified selection criteria were enrolled between May $2^{\text {nd }} 2006$ and April $30^{\text {th }}$ 2007. Mean age $( \pm S D)$ at inclusion was $55.7 \pm 13.0$ years and median age 56.2 years (range: $0.8-85.2$ ). Mean $( \pm S D)$ body mass index (BMI) was $25.0 \pm 5.5 \mathrm{~kg} / \mathrm{m}^{2}$ and median BMI $24.2 \mathrm{~kg} / \mathrm{m}^{2}$ (range: 12.6-58.4).

The patients presented various cancers, predominantly breast (314), gastrointestinal (125), lung (79), upper airways (77), gynaecological other than breast (77), urological (64) and sarcomas (47). The cancer was in progression in 199 patients. A total of 213 patients had previously undergone radiotherapy (136), chemotherapy (127) or surgery (49) for cancer. WHO Performance status was 0 or 1 in 576/649 (grade 0: 366 , grade 1:210, grade 2: 46, grade $3: 27 ; 166$ missing data). Anticoagulant treatment was ongoing in 115/688 patients (127 missing data).

\section{Materials}

The TIVAPS inserted in most patients $\left(687 / 811 ; 4\right.$ missing data) was a Polysite ${ }^{\circledR}$ 3007 (Laboratoires Perouse, France), a further 122 patients receiving a Polysite ${ }^{\circledR}$ 3008 (Laboratoires Perouse, France). Both these devices comprise a titanium/polyoxymethylene mini-chamber with a silicone catheter. A Celsite ST305 (B. Braun Medical, Germany) was inserted in two patients and an Arrow 14G 20 (Arrow International) in one patient. 


\section{TIVAPS placement}

Antiseptic precautions prior to TIVAPS placement were well respected, all patients for whom these data were available having taking an antiseptic shower in hospital beforehand $(680 / 815 ; 135$ missing data) and undergone disinfection of the insertion zone (730/815; 85 missing data).

The TIVAPS was inserted under local anaesthesia in 736/805 patients (10 missing data). Catheterisation was accomplished using the first vein selected in 648/780 patients ( 35 missing data) and a second vein in a further 117 patients. The veins selected initially were principally the external jugular vein (404/808 patients; 7 missing data) and the cephalic vein (367/808). These were also the predominant veins finally catheterised (external jugular vein: 405/791 patients; 24 missing data; cephalic vein: 339/791 patients). The TIVAPS was placed via an incision at the boundary between the deltoid and pectoralis major muscles for cephalic vein catheterisation and otherwise above the pectoralis major muscle.

The device was inserted by a junior surgeon in $406 / 815$ patients, by a senior surgeon in 307 patients and by both in 102 patients. TIVAPS insertion was generally considered to be easy (679/760 patients; 24 missing data), requiring a median of 30 min (90 missing data). The procedure took longer when accomplished by a junior surgeon (mean \pm SD: $36 \pm 17$ min vs. $28 \pm 16$ min, $p<0.00001$ ).

After TIVAPS insertion, the position of the catheter was checked radiologically in $812 / 815$ patients, the permeability of the system being checked in $763 / 766$ patients (49 missing data). 
Use of the TIVAPS

In 53 patients, the TIVAPS was never used. In the remaining 762 patients, the median and mean $( \pm S D)$ interval between insertion of the TIVAPS and its first use was respectively 8.0 days (range: $0-135$ ) and $12.4 \pm 14.6$ days. In most patients (771/797; 18 missing data) the TIVAPS was inserted to facilitate chemotherapy administration. Data on ease of use of the TIVAPS, assessed on a scale of 0 (easy) to 7 (difficult) was available for 460 patients (302 missing data) and indicated facility of use, the score being 0 in 415 patients and 1 in 30 patients.

\section{Complications}

No deaths occurred during the study. Complications following TIVAPS placement were experienced by $131 / 815$ patients, principally infections, inflammation, local haematoma and local skin disorders (Table 1). The median time to onset of infection was 66 days (range: 1-379). Early infections were rare (five incidences within the first 15 days and five between 15 days and one month, in each case prompting two premature device removals). The remaining infections (34 cases) occurred after more than one month, leading to premature device removal in 15 cases. Severe (grade 3) complications comprised documented infection (40; 4 cases not graded), port expulsion (15), catheter migration (6; one case not graded) and venous thrombotic syndrome (6). Overall, complications (principally infection and port expulsion) necessitated premature device removal in 55 patients after a mean ( \pm SD) of $4.5 \pm$ 3.5 months (median: 3.7 months; range: $0.2-12.0$ ). In 64 patients, the TIVAPS was removed before the end of the two-year follow-up period owing to completion of chemotherapy, the median and mean ( \pm SD) intervals between TIVAPS insertion and removal being respectively 7.5 months $(3.7-12.0)$ and $7.7 \pm 2.6$ months. 


\section{Risk factors for complications}

\section{Patient characteristics}

Neither the overall incidence of complications nor the rate of premature device removal differed significantly according to baseline performance status, baseline BMI, type of cancer, or prior treatment for cancer. The incidence of haematomas was not significantly higher with anticoagulant use.

\section{TIVAPS placement procedure}

The ease of TIVAPS placement, overall incidence of complications and incidence of premature device removal did not differ significantly according to the vein finally catheterised (cephalic vein vs. external jugular vein). However, external jugular vein catheterisation resulted in higher rates of inflammation (20/405 patients vs. $3 / 339$; $\mathrm{p}=0.003)$ and port expulsion (13/405 vs. $2 / 339 ; \mathrm{p}=0.02)$.

The overall incidence of complications was also not significantly affected by success or failure to access the vein initially selected, experience of the surgeon, ease of TIVAPS insertion, duration of the procedure or type of TIVAPS implanted (Polysite ${ }^{\circledR} 3007$ vs. Polysite ${ }^{\circledR}$ 3008).

In contrast, the interval between TIVAPS implantation and first use had a statistically significant impact on the overall complication rate, and the frequency of skin disorders and infections. The median intervals between device implantation and first use in patients with and without complications were respectively 6 days (range 0$53)$ and 8 days (range $0-135)$. The mean ( \pm SD) intervals between device placement and first use were respectively $13.1 \pm 15.2$ days and $9.1 \pm 9.7$ days $(p=0.005)$. The overall incidence of complications progressively diminished with increasing interval 
between TIVAPS insertion and first use, being $24.4 \%$ (39/160 patients) when the interval was 0-3 days, $17.1 \%(33 / 193)$ when it was $4-7$ days and $12.1 \%(49 / 405)$ when it was over 7 days $\left(p<0.01 ;\right.$ chi $^{2}$ test).

Local skin disorders were experienced by $6.9 \%(11 / 160), 4.1 \%(8 / 193)$ and $0.7 \%$ (3/405) patients, respectively, when the interval between TIVAPS placement and its first use was 0-3 days, 4-7 days and over 7 days $(p<0.001)$. Similarly, infection was documented in $10.6 \%(17 / 160), 6.7 \%(13 / 193)$ and $2.0 \%$ (8/405) patients, respectively, when the TIVAPS was first used 0-3 days, 4-7 days and more than 7 days after its insertion $(\mathrm{p}<0.0001)$.

Multivariate logistic regression analysis showed that the complication rate increased with difficulty in TIVAPS insertion when the interval between insertion and first use was $\leq 7$ days, but not when it was 8 days or more. The rate of premature device removal owing to complications was $30 / 353$ when the interval between insertion and first use was less than 8 days and 20/405 when it was 8 days or more. This difference was at the limit of statistical significance $\left(p=0.05, C^{2} i^{2}\right.$ test) and no longer significant when the Yates correction was applied.

\section{Quality of life and patient satisfaction with TIVAPS placement and use}

Although all adult patients were invited to complete the EORTC QLQ-C30 quality of life questionnaire, just before TIVAPS placement and the first and fourth cycles of chemotherapy, and the questionnaire on satisfaction just before the fourth chemotherapy cycle, only a minority did so. Depending on the item considered, between 291 and 319 patients were evaluable for the comparison of QLQ-C30 quality of life scores between TIVAPS insertion and first use. 
No decrease in global health status or quality of life was evident, although small but statistically significant changes were seen in certain individual functional scales (decrease in physical, role, emotional and social functioning) and one of the symptom scales (increase in pain). Comparison of the scores between TIVAPS insertion and the start of the fourth chemotherapy cycle (150-160 patients evaluable depending on the item) gave similar results. Global health status and quality of life remained unchanged, but there was a statistically significant decrease in scores for physical $(p=0.001)$ and emotional $(p=0.0002)$ functioning.

Only 171 patients responded to the questionnaire on satisfaction just before the fourth course of chemotherapy. Concerning TIVAPS-related pain, 100/167 patients stated that they felt no pain, 47 declaring slight pain. Similarly, 115/169 patients maintained that the device was not an obstacle to performing any activities, 43 considering that it only slightly hampered their activities. Most patients $(118 / 166)$ considered that the scars were at least satisfactory from an aesthetic standpoint and that the scars, the port and the attached catheter did not impair their ability to dress themselves and were not overly visible. Patients in whom TIVAPS insertion had involved cephalic vein access (one scar) rated the aesthetic appearance of their scars significantly more highly than those in whom the external jugular vein had been accessed $\left(p=0.01\right.$ chi $^{2}$ test), the latter procedure resulting in two scars. They were also significantly less bothered by visibility of the catheter $\left(p=0.001 ;\right.$ chi $^{2}$ test $)$. 


\section{Discussion}

\section{Incidence of complications}

The overall incidence of complications in our study (16.1\%) was similar to those reported after TIVAPS implantation in cancer patients by Wolosker et al.[13] (17.7\%), Leinung et al.[14] (15.4\%) and Araújo et al.[10] (15.8\% in the case of subclavian vein access). Lower rates were reported by Hoareau-Gruchet et al.[15] (7.4\%), Hsieh et al.[11] (7.5\%), Vardy et al.[9] (8.2\%) and Araújo et al.[10] in the case of internal jugular vein access (7.6\%), Hartkamp et al.[7] reporting a higher rate (25.2\%). As in other studies,[7,9,11,13,14] the main complication observed in our study was infection, occurring in $5.3 \%$ of patients and accounting for half the total number of premature device removals.

\section{Risk factors for complications}

Among the wide range of variables investigated, only the time elapsing between implantation of the TIVAPS and its first use had a statistically significant effect on the overall rate of complications. The complication rate was significantly higher when the interval between implantation and first use was at least 8 days and a strong trend towards a higher incidence of premature removal of the TIVAPS due to complications was also observed. To the best of our knowledge, this relationship has not been reported in previous studies and warrants further investigation. One possible explanation for these findings might be that healing of the incision made to inset the device is less likely to be complete and fully capable of withstanding the strains involved in TIVAPS use when this occurs less than 8 days after device placement. In 
cancer patients, the administration of aggressive cytotoxic drugs might then further increase the risk of complications by hindering the completion of wound healing.

In our study, the vein catheterised was predominantly either the external jugular vein or the cephalic vein, these veins similarly being the principal site of TIVAPS insertion in the studies reported by Wolosker et al. [13] and Hsieh et al. [11], respectively. The overall complication rate did not differ significantly according to the vein accessed. However, both inflammation and port expulsion were significantly less frequent when the the cephalic vein was catheterised. Patient satisfaction was also greater with cephalic vein catheterisation, with regard to both the esthetic appearance of the incision scar and visibility of the catheter. The results of previous studies vary, showing either an effect [10] or no effect $[5,6,11]$ of the vein accessed on complication rates, but the veins compared differ from one study to another.

\section{Quality of life}

The observational and routine practice nature of our study probably contributed to the rather high numbers of missing data for certain variables, particularly those concerning the impact of TIVAPS insertion and use on quality of life and patient satisfaction with these procedures. The questionnaires addressing these issues were proposed at particularly stressful moments (just before TIVAPS placement and at the time of the first and fourth chemotherapy cycles), when apprehension and fear of pain may have discouraged communication. Bearing in mind the limitation that our results concern a minority of the patients included, they coincide with those reported by Kreis et al.[16], suggesting a generally high level of satisfaction with TIVAPS in terms of repercussions on everyday activities, aesthetic impact and pain. No significant decrease in overall health status or quality of life was detected. 


\section{Conclusions}

The results of our study suggest that respect of an approximately one week interval between the implantation and first use of TIVAPS for administration of chemotherapy may reduce the likelihood of complications and the need for premature device removal. If confirmed by further investigations, this finding may be worth taking into account in routine clinical practice. Placement of the TIVAPS in the cephalic vein rather than the external jugular vein appears to be preferable in terms of the risk of inflammation and port expulsion, as well as aesthetic considerations. 


\section{Acknowledgements}

The authors thank all the medical, nursing and auxiliary staff of the Oscar Lambret Regional Anticancer Centre for their dedicated teamwork during this study, Muriel Chapoutier for monitoring the study, Brice Dubois, Samia Swyndauw and Jean-Pierre Meurant for their valuable assistance with data management, and the Clinical Research Unit (in particular, Stéphanie Clisant). 
Page 18/23

\section{Conflict of interest statement}

The authors declare that they have no financial or personal relationships with other people or organisations that could have inappropriately influenced or biased their work. 


\section{Role of the funding source}

The study was partially funded by Perouse Medical, a company manufacturing implantable venous access port systems. This funding was used to remunerate the clinical research personnel involved in the project. 


\section{References}

1. Vescia S, Baumgärtner AK, Jacobs VR, et al. Management of venous port systems in oncology: a review of current evidence. Ann Oncol 2008;19:9-15.

2. Biffi R, Pozzi S, Agazzi A, et al. Use of totally implantable central venous access ports for high-dose chemotherapy and peripheral blood stem cell transplantation: results of a monocentre series of 376 patients. Ann Oncol 2004;15:296-300.

3. Groeger JS, Lucas AB, Thaler HT, et al. Infectious morbidity associated with long-term use of venous access devices in patients with cancer. Ann Intern Med 1993;119:1168-74.

4. Maki DG, Kluger DM, Crnich CJ. The risk of bloodstream infection in adults with different intravascular devices: a systematic review of 200 published prospective studies. Mayo Clin Proc 2006;81:1159-71.

5. Yildizeli B, Lacin T, Batirel HF, Yüksel M. Complications and management of long-term central venous access catheters and ports. J Vasc Access 2004;5:174-8.

6. Biffi R, Orsi F, Pozzi S, et al. Best choice of central venous insertion site for the prevention of catheter-related complications in adult patients who need cancer therapy: a randomized trial. Ann Oncol 2009;20:935-40.

7. Hartkamp A, van Boxtel AJ, Zonnenberg BA, Witteveen PO. Totally implantable venous access devices: evaluation of complications and a prospective comparative study of two different port systems. Neth J Med 2000;57:215-23. 
8. Heit JA. Cancer and venous thromboembolism: scope of the problem. Cancer Control 2005;12(Suppl 1):5-10.

9. Vardy J, Engelhardt $\mathrm{K}$, Cox K, et al. Long-term outcome of radiological-guided insertion of implanted central venous access port devices (CVAPD) for the delivery of chemotherapy in cancer patients: institutional experience and review of the literature. $\mathrm{Br} \mathrm{J}$ Cancer 2004;91:1045-9.

10. Araújo C, Silva JP, Antunes $P$, et al. A comparative study between two central veins for the introduction of totally implantable venous access devices in 1201 cancer patients. Eur J Surg Oncol 2008;34:222-6

11. Hsieh $\mathrm{C}-\mathrm{C}$, Weng $\mathrm{H}-\mathrm{H}$, Huang $\mathrm{W}-\mathrm{S}$, et al. Analysis of risk factors for central venous port failure in cancer patients. World J Gastroenterol 2009;15:4709-14.

12. Hung M-C, Chen C-J, Wu K-G, Hung G-Y, Lin Y-J, Tang R-B. Subcutaneously implanted central venous access device infection in pediatric patients with cancer. J Microbiol Immunol Infect 2009;42:166-71.

13. Wolosker N, Yazbek G, Nishinari K, et al. Totally implantable venous catheters for chemotherapy: experience in 500 patients. São Paulo Med J 2004;122:14751.

14. Leinung S, Würl P, Anders K, Deckert F, Schönfelder M. [Port catheter fractures in 361 implanted port systems. Analysis of the causes - possible solutions review of the literature] [article in German]. Chirurg 2002;73:696-9.

15. Hoareau-Gruchet F, Rtail R, Sulaj H, Khimetkina A, Reyt E, Righini CA. [Complications after insertion of a totally implantable venous access port in 
patients treated with chemotherapy for head and neck squamous cell carcinoma] [article in French]. Ann Otolaryngol Chir Cervicofac 2009;126:43-52.

16. Kreis H, Loehberg CR, Lux MP, et al. Patients' attitudes to totally implantable venous access port systems for gynecological or breast malignancies. EJSO 2007;33:39-43. 
Table 1. Complications during TIVAPS use

\begin{tabular}{|c|c|}
\hline \multirow[t]{2}{*}{ Complication } & No. of patients \\
\hline & $\mathrm{N}=815$ \\
\hline External complications & 111 \\
\hline Inflammation & 28 \\
\hline Local haematoma & 26 \\
\hline Local skin disorders & 23 \\
\hline Pain & 19 \\
\hline Port exteriorisation & 15 \\
\hline Internal complications & 97 \\
\hline Documented infection & 44 \\
\hline Extravasation & 15 \\
\hline Mechanical problems & 13 \\
\hline Port obstruction & 11 \\
\hline Venous thrombotic syndrome & 7 \\
\hline Catheter migration & 7 \\
\hline Complications prompting premature TIVAPS removal & 55 \\
\hline Documented infections related to TIVAPS & 19 \\
\hline Port expulsion & 14 \\
\hline Catheter migration & 6 \\
\hline Venous thrombotic syndrome & 5 \\
\hline Mechanical problems & 3 \\
\hline Skin disorders & 2 \\
\hline Pain syndrome & 2 \\
\hline Extravasation & 2 \\
\hline Infection not related to TIVAPS & 1 \\
\hline Inflammatory syndrome & 1 \\
\hline
\end{tabular}

